\title{
SOBRE A RESPONSABILIDADE DE SER E ESTAR NO MUNDO: UMA ENTREVISTA COM PILAR DEL Río
}

http://dx.doi.org/10.11606/issn.2175-3180.v13i24p160-167*

Por Bianca Rosina Mattia ${ }^{\mathrm{I}}$

Nascida em Sevilha, filha de Carmem e de Antônio, Pilar del Río é a mais velha de quinze irmãos. Jornalista, tradutora e Presidenta da Fundação José Saramago, recebeu recentemente o Prêmio Luso-Espanhol de Arte e Cultura pelo reconhecimento de seu trabalho à frente da Fundação. Nesta entrevista, fala com muita lucidez sobre a leitura da obra de Saramago, com quem esteve casada até 2010, ano do falecimento de seu companheiro. Pilar del Río não só é lúcida, mas também é veemente, se recuperarmos a oportuna voz de Saramago: "Eu creio que ela nasceu veemente, não há nada a fazer contra isso. Nem há qualquer interesse em fazer algo contra isso, ela é assim como é.". ${ }^{1}$ Em sua fala, Pilar discorre sobre literatura, sobre a conjuntura política, sobre feminismo, sobre seu trabalho à frente da Fundação e, em especial, sobre o romance inacabado de

\footnotetext{
* Publicada originalmente na revista Desassossego, v. 9, n. 17, jun/2017:

https://www.revistas.usp.br/desassossego/issue/view/10348

DOI original: http://dx.doi.org/10.11606/issn.2175-3180.v0i17p223-230

I Universidade Federal de Santa Catarina, Florianópolis, Brasil.

${ }^{1}$ José Saramago, em entrevista a Miguel Gonçalves Mendes, publicada no livro José e Pilar: conversas inéditas, em 2012, pela Companhia das Letras.
} 
JoséSaramago Alabardas, alabardas, Espingardas, espingardas², publicado pela primeira vez em 2014, tanto em Portugal quanto no Brasil.

BIANCA ROSINA MATTIA: Em uma de suas entrevistas, você falou que a obra de José Saramago empodera os seres humanos. Saramago costumava dizer que escrevia para desassossegar os seus leitores. Gostaria que começasse por falar sobre o poder da literatura. O que podem as palavras? Qual é a função da literatura?

PILAR DEL RÍO: Não sei se a Literatura tem que ser funcional. Talvez a literatura não sirva para nada, ou talvez outorgue às gerações de leitores a dimensão da memória. Acho que poderíamos viver sem literatura, de fato milhões de pessoas vivem sem ela, mas sem os livros que lemos e guardamos na nossa experiência leitora, o mundo seria chato. A literatura confere profundidade à inteligência e sensibilidade aos corpos. ${ }^{3}$

BRM: Sobre os últimos escritos de José Saramago, a Pilar foi a primeira leitora de Alabardas. ${ }^{4}$ Como foi essa experiência: ser a primeira leitora do último romance de Saramago?

$P d R$ : Ser a primeira leitora de José Saramago era uma consequência natural da vida em comum e da cumplicidade que escolhemos partilhar, não tem outro simbolismo. Olhando agora vejo aquilo com assombro, um presente fascinante que quase que me aterroriza: tive nas mãos as primeiras linhas de obras magníficas, as dúvidas e as façanhas, assisti o dia a dia da construção de uma obra colossal. Em relação a "Alabardas", José Saramago sempre teve em conta que a morte podia impedi-lo de acabar o livro, por isso deixou as anotações. Ele não queria morrer sem essa última reflexão sobre a responsabilidade. Que é o argumento central do último trabalho literário de José Saramago: a responsabilidade individual.

\footnotetext{
2 "Alabardas, alabardas, Espingardas, espingardas", romance inacabado de José Saramago, com publicação póstuma em 2014, é objeto de minha dissertação de mestrado, em andamento, no Programa de Pós- Graduação em Literatura da Universidade Federal de Santa Catarina.

${ }^{3}$ A tradução das respostas de Pilar del Río é de Ricardo Viel, jornalista e assessor de comunicação da Fundação José Saramago, em Lisboa, Portugal.

4 Alabardas, Alabardas, Espingardas, Espingardas, romance inacabado de José Saramago, foi publicado em 2014 no Brasil, pela Companhia das Letras e, em Portugal, pela Porto Editora.
} 
BRM: Quando da publicação de Alabardas, no editorial da revista Blimunda ${ }^{5}$ [publicada em setembro de 2014], você afirmou que Alabardas não é um testamento, é o livro com o qual José Saramago queria fechar o seu percurso. Como percebe esse fechamento de percurso literário com a temática trazida por Alabardas? O legado deixado por Saramago seria o mesmo sem o Alabardas?

$P d R:$ O legado de José Saramago não seria o mesmo sem "Alabardas, Alabardas, Espingardas, Espingardas": como poderia ser igual retirar da obra de um autor um livro e um empenho moral e literário? Pelo contrário, José Saramago sabia que lhe restava pouco tempo de vida e, ainda assim, abordou a tarefa titânica de descrever o caos que a desumanidade gera, e o fez como se tivesse nascido só para isso, como se o destino do mundo dependesse do seu trabalho. Para levar a cabo essa urgência literária e moral, escolheu contar a vida de um modesto cidadão, um homem exemplar, que cumpre com a sociedade respeitando todas as normas e leis, que é bom no seu trabalho sem se perguntar a quem e para quem serve aquilo que faz. E assim, tranquilamente, participa da fabricação de armas, sem jamais perguntar-se qual é o destino desse seu trabalho - que é a morte de outros. E para que seu negócio prospere necessita de muitos conflitos, que de alguma forma são incentivados, porque é preciso seguir fabricando... Enfim, é um relato do nosso mundo, agora mais do que nunca. José Saramago o viu, com a capacidade antecipatória que têm os pensadores e com a capacidade expressiva que têm os escritores. Teremos nós a capacidade para o ler? Essa é a questão. José Saramago cumpriu, encerrou a sua vida sem ceder à comodidade ou à indiferença. Que cada um pense o que está fazendo por si próprio ou própria.

BRM: Recentemente li uma declaração sua de que há uma obra de teatro e vários contos de Saramago ainda inéditos. Como a Pilar entende a importância de disponibilizar, até mesmo os escritos que José Saramago não havia concluído [como é o caso de Alabardas], ao público leitor?

$P d R:$ Há contos e também há conferências pronunciadas em determinados lugares que nunca foram publicadas. E há especialistas trabalhando nesse material para ver de que maneira será publicado. Claro, assumo

\footnotetext{
5 Revista digital editada e publicada pela Fundação José Saramago. Disponível em: $<$ https://www.josesaramago.org/category/blimunda/>.
} 
inteiramente a responsabilidade de publicar "Alabardas", que não é uma obra inacabada: está acabado o que José Saramago escreveu e o leitor reconhece a José Saramago nesse texto e à urgência de dizer as coisas que lhe era característico. Há alguma norma acadêmica que diga que esse texto não deveria ser lido por quem esteja interessado? A propósito, alegra-me saber que está trabalhando este livro, como leitora lhe agradeço. E espero que a universidade, lugar onde se ensina literatura e se estuda a José Saramago, consiga perceber a luta agônica de quem não quis morrer sem dizer tudo. E o conseguiu.

BRM: Sobre as novas edições de livros já publicados de Saramago, como a versão digital do Conto da Ilha Desconhecida ${ }^{6}$, em uma edição ilustrada por Juergen Cannes; também a edição da crônica $\mathrm{O}$ Lagarto $^{7}$, com xilogravuras do brasileiro José Borges; é uma tentativa de manter a obra de Saramago viva? A literatura precisa se adaptar aos novos leitores?

$P d R:$ Não sei se literatura necessita novos leitores ou os leitores necessitamos a literatura. Mas sim, experimentamos novos projetos porque não nos sentimos com capacidade para recusar um livro com J. Borges. Tentamos estar vivos e manter o pulso criativo daqueles que nos fazem grandes. É a responsabilidade que temos como leitores e seres humanos. Trabalhamos em projetos diferentes porque é a nossa responsabilidade: o que não fizermos ficará sem ser feito.

BRM: Especificamente sobre a edição e publicação de Alabardas: o livro já foi publicado, até o momento, em dez países. Todas as edições de Alabardas apresentam a mesma composição: o romance inacabado, as anotações de José Saramago, as ilustrações de Günter Grass e os ensaios de Fernando Gómez Aguilera e de Roberto Saviano. Algumas outras edições acrescentam ensaios de outros autores. Gostaria de que falasse como se deu o processo editorial de composição do livro. Foi pensado inicialmente pela Pilar, ou partiu de uma conversa com os editores? A escolha dos demais autores que escrevem no livro foi sua?

\footnotetext{
${ }^{6}$ Em formato ePub, a edição especial com ilustrações de Juergen Cannes foi editada e publicada pela Companhia das Letras em 2016.

${ }^{7}$ A crônica "O Lagarto", que integra o livro A bagagem do viajante, de José Saramago, foi publicada em uma edição com xilogravuras de José Francisco Borges, pela Companhia das Letrinhas, em 2016.
} 
$P d R$ : Foi pensado com editores e responsáveis da Fundação. Escolheu-se nomes que representam a vontade emancipatória que a literatura tem e que estão relacionados a José Saramago. Grass foi editado em Portugal por Saramago, Saviano pertence à estirpe valente que José Saramago valorizava por cima de todo, e sobre ele tinha escrito e falado. Fernando Gómez Aguilera é o depositário do legado de José Saramago, recebeu papéis e confidências, de alguma maneira podemos dizer que é o herdeiro da vontade literária de José Saramago.

BRM: O editor Manuel Alberto Valente, da Porto Editora, afirmou aos leitores que esperassem por Alabardas um manifesto pela paz. Como lhe soa pensar o Alabardas como um manifesto?

$P d R$ : Acho que é um manifesto literário, um romance, contra o abjeto que é viver sem usar a razão e ignorando a consciência embora sejamos, ao menos em teoria, seres com razão e consciência. Alabardas é um romance e uma contribuição ética que aparece publicada no momento em que nós, enquanto sociedade, nos apagamos entre os gritos dos que perdem tudo em guerras absurdas e o poder total de quem controla tudo e organiza conflitos para manter a sua hegemonia. E no meio estão os cidadãos, cúmplices e vítimas ao mesmo tempo, massa silenciosa ou distraída, sem consciência do seu poder, do importante que é dizer não. Insisto mais uma vez: falo da responsabilidade de cada um, essa que a literatura coloca de manifesto.

BRM: No discurso ${ }^{8}$ pronunciado no Banquete Nobel a 10 de dezembro de 1998, José Saramago afirmou que temos de reivindicar o dever dos nossos deveres, e então expressou o desejo pela elaboração da Carta dos Deveres Humanos. À frente da Fundação, a Pilar assumiu a realização dessa vontade. Gostaria que falasse um pouco sobre como está a situação dessa proposta e se já há previsão para o encaminhamento da Carta às Nações Unidas.

\footnotetext{
${ }^{8} \mathrm{O}$ discurso está disponível no site da Fundação José Saramago: $<$ https://www.josesaramago.org/discurso-pronunciado-por-jose-saramago-no-dia-10-dedezembro-de-1998-no-banquete-premio-nobel/>.
} 
PdR: Estamos trabalhando nessa Declaração Universal de Deveres Humanos. Claro que Alabardas se inscreve nessa linha que José Saramago destacou no discurso do Nobel. Linha que percorre toda a sua obra, desde o Manual de Pintura e Caligrafia, O Ano da Morte de Ricardo Reis, o Evangelho segundo Jesus Cristo, Ensaio sobre a Cegueira e sobre a Lucidez, A Caverna, Caim... Todos os romances de José Saramago são meditações sobre a responsabilidade. Esperamos que até o final de 2017 a carta dos deveres, iniciativa que é feita com a UNAM do México, esteja redigida.

BRM: Mudando um pouco de assunto, durante o processo de impeachment da Presidenta Dilma Rousseff, uma cena do filme José e Pilar [de Miguel Gonçalves Mendes, 2010] repercutiu muito nas redes sociais: aquela em que a Pilar adverte o entrevistador que lhe chame: Presidenta, no feminino. No Brasil, também houve grande recusa ao uso do substantivo no feminino para o cargo desempenhado por uma mulher. Exigir que the chamem Presidenta é um ato de resistência para nós mulheres? Para a Pilar, quais são os maiores desafios e/ou barreiras enfrentados pelas mulheres na luta contra o machismo?

$P d R$ : O idioma pode ser uma arma de destruição massiva. Não usar o feminino em determinados níveis de representação social é condenar a mulher a um papel não hegemônico, assimétrico, sob o padrão de dominação masculina. É muito importante, é fundamental para nossa construção mental, que o poder também tenha femininos. Obviamente, Dilma é presidenta. E quem não o reconhece assim é porque quer ser mantido na educação patriarcal ou é vítima do patriarcado. A linguagem está para servir as pessoas, não para que as mulheres sofram de sua construção patriarcal.

BRM: Sobre a presença feminina na obra de José Saramago, disse o autor que sempre há uma mulher a sustentar cada um de seus romances. Em Alabardas, temos Felícia, que é quem dá voz àquela que seria a última frase do romance: Vai à merda. Como a mulher Pilar del Río lê as personagens femininas de Saramago, especialmente esta última, Felícia, e esse final por ela proferido? 
$P d R:$ "Vai à merda" é a única conclusão lógica aos atropelos que se cometem contra os seres humanos. Quando as invocações à razão e à consciência são ignoradas de maneira tão eloquente pelo poder, pelos poderes econômicos, políticos e religiosos, a maior demonstração de sensatez é mandá-los à merda. E o faz quem nasceu de si mesma de tal maneira que até se batizou: de berta ${ }^{9}$ passou a ser Felícia: quer maior poema que este?

BRM: Sobre seu trabalho como tradutora, a Pilar disse certa vez: Gosto muito de traduzir, é partilhar amores. Como foi traduzir Alabardas?

$P d R$ : Foi duro. Preciso de mais tempo para pensar nessa tradução sem que me traga uma dor à alma, ainda não consigo.

BRM: Recentemente lhe foi atribuído, por unanimidade, o Prêmio LusoEspanhol de Arte e Cultura pelo reconhecimento de seu trabalho como criadora e Presidenta da Fundação José Saramago. Para o seu trabalho, o que significou receber tal distinção?

$P d R$ : Acho que é o reconhecimento aos que chamamos a José Saramago de nosso e que sabemos que sua inteligência e sensibilidade são patrimônio dos leitores, sem bandeiras nem fronteiras. Alegra-nos que se sabia que os leitores da Península Ibérica somos produtos de culturas misturadas, diversas e plurais. Compartilhamos o prêmio com portugueses e espanhóis que trabalham na Fundação e em José Saramago.

BRM: Para finalizar, o que a Pilar diria aos pesquisadores e estudantes da obra de José Saramago?

$P d R$ : Que leiam. Que cada um leia a partir da sua personalidade, sem regras nem preconceitos. Que entendam o estilo literário e que ouçam a música e a respiração de cada página. Que cada livro leva dentro o autor, que o melhor é que entremos em cada livro e celebremos o encontro total com os atributos que nos são próprios, a capacidade de entender, a

\footnotetext{
${ }^{9}$ Sobre felícia, escreve Saramago no romance: “[...], tendo sido batizada como berta, que era o nome da avó materna, passou a chamar-se oficialmente felícia para não ter de carregar toda a vida com a alusão direta ao canhão ferroviário alemão que ficou célebre na primeira guerra mundial por bombardear paris de uma distância de cento e vinte quilómetros." (SARAMAGO, 2014, p.10).
} 
possibilidade de desfrutar, a vontade de sentir com outro que, sendo nosso semelhante, também é um mestre.

\section{REFERENCIAS}

Blimunda, n. 28. Lisboa: Fundação José Saramago, setembro de 2014.

Disponível em: <http://www.josesaramago.org/wpcontent/uploads/2014/09/blimunda_28_setembro_2014_1.pdf $>$. Acesso em: 28 nov. 2016.

JOSÉ e Pilar: os dias de José Saramago e Pilar del Río. Realização: Miguel Gonçalves Mendes. Produtores: Agustín Almodóvar; Bel Berlink; Esther García; Fernando Meirelles; Miguel Gonçalves Mendes. Produção: JumpCut; El Deseo; 02 Filmes. Lisboa: JumpCut, 2010. (DVD 1: 125min; DVD 2: 160min).

MENDES, Miguel Gonçalves. José e Pilar: conversas inéditas. Tradução das falas de Pilar em espanhol por Rosa Freire d'Aguiar. São Paulo: Companhia das Letras, 2012.

SARAMAGO, José. A bagagem do viajante: crônicas. São Paulo: Companhia das Letras, 1996.

SARAMAGO, José. Alabardas, alabardas, espingardas, espingardas: com textos de Fernando Gómez Aguilera, Luiz Eduardo Soares, Roberto Saviano. São Paulo: Companhia das Letras, 2014.

SARAMAGO, José. O conto da ilha desconhecida. São Paulo: Companhia das Letras, 2016 (ePub).

SARAMAGO, José. O lagarto: com xilogravuras de J. Borges. São Paulo: Companhia das Letrinhas, 2016.

\section{Licença: () (1) ()}

Concepção e realização da entrevista:

Bianca Rosina Mattia

Doutoranda do Programa de Pós-Graduação em Literatura da Universidade Federal de Santa Catarina.

Contato: biancamattia@gmail.com

(D) : https://orcid.org/0000-0002-0136-1241 